\title{
THE DURABILITY OF PASSIVE DIPHTHERIA IMMUNITY.
}

\author{
By William Bulloch.
}

From the British Institute of Preventive Medicine.

THE question of the durability of the immunity produced by the injection of antitoxic sera is of importance both clinically and experimentally. The experiment, the results of which are given below, was undertaken to determine at what remote periods, after the injection of a definite number of diphtheria antitoxin units, the antitoxin could be demonstrated in the blood of the recipient. An ass was chosen, chiefly on account of its size, and 25,000 normal units of serum were introduced subcutaneously on the side of the neck. At various periods blood was drawn from the jugular vein, and the serum carefully tested by the method of Ehrlich.

Hitherto the results of different observers have varied in regard to the durability of passive immunity. Working with ricin, Ehrlich $\left(^{1}\right)$ found that the antiricin body was preserved for a relatively long period in the cireulation, but that the durability was inconstant and depended on the amount of antiricin introduced.

In the case of diphtheria, Behring $\left(^{2}\right)$ found that in goats which had received large quantities of antitoxin (50 c.c. of a serum 500 times normal strength) the maximum antitoxicity exhibited by the blood was shown on the fourth day, and from this time it rapidly diminished, but was still present in considerable quantity at the end of twenty-three days.

In man, Passini ( ${ }^{(3)}$ found (four cases) that after a preventive inoculation of 200 units it was impossible to demonstrate any antitoxin in the serum after eleven or twelve days. Behring $\left({ }^{4}\right)$ has, however, demonstrated antitoxin in the blood of children three to four weeks after a dose of 250 units, and elinically it has been found that a dose of 200 units protects for about four weeks (Rubens ${ }^{5}$ ).

Recently, Bomstein $\left(^{6}\right)$, using much larger quantities of antitoxin (8000 to 10,000 units) in dogs, found that, even on the second day following the injection, half the antitoxin had disappeared from the serum, and that by the eighteenth day it was completely gone.

The donkey used by us received 100 e.c. of a $250 \times$ serum 
(25,000 units). Prior to this the serum of the animal was tested, as several observers (Wassermann, Orlowski, Meade Bolton, and Cobbett) have found that the blood serum of animals and human beings who have never had diphtheria may contain appreciable quantities of antitoxin.

The toxin used in the experiment was the same throughout, and was conserved with toluol. The test dose was obtained by standardising against various samples of Höchst serum. The constitution of the toxin, as expressed by Ehrlich's formula, was-

$$
\begin{aligned}
& \text { D.T.N. } \cdot 05 \text { c.c. }\left(\cdot 2 \mathrm{M}^{250}\right) \\
& \text { L+ } \cdot 60,=3 \text { lethal doses. } \\
& \text { Lo } \cdot 30,==1 \cdot 5 \\
& \hline \text { D } \\
& \hline
\end{aligned}
$$

The older method of Ehrlich with the Lo dose was the test used, as the newer method with the $\mathrm{L}+$ dose had not been published at the time the experiment was made.

Before the introduction of the antitoxin the serum of the ass was shown to be devoid of protective properties, in so far that 3 c.c., 5 c.c., and 10 c.c. failed to prevent local infiltration and death in guinea-pigs which received the Lo dose of $\cdot 3$ c.c.

As the amount of antitoxin present in the blood after the introduction of serum was slight, it has been estimated as units in 10 c.c.

First venesection.-Half an hour after the subcutaneous injection of 25,000 units of antidiphtheritic serum it was found that the serum of the ass contained 2 units per 10 c.c.

Second venesection.-At the end of twenty-four hours the serum contained 16 units in 10 c.c.

Third venesection.-Four days after injection, the antitoxin had fallen to 11 units in 10 c.c.

Fourth venesection.-On the twenty-fourth day showed a fall to 7.5 units.

Fifth venesection. - On the forty-eighth day, serum $=5 \cdot 5$ units.

Sixth venesection. - On the sixtieth day, serum $=4-5$ units.

Seventh venesection.-On the seventy-seventh day, serum $=3-4$ units.

Eighth venesection.-On the hundredth day, serum $>1$ unit.

Ninth venesection.-On the hundred and twenty-sixth day, serum $<1$ unit.

After the introduction of anti-diphtheria serum subcutaneously, there was shown to be a rapid entry into the blood stream, beginning almost immediately, and reaching a maximum about the end of twenty-four hours. Following this there was a rapid decrease up to the fourth day, and from this time onwards the antitoxin suffered a progressive but slow diminution, being still present in minute quantity at the end of 100 days (see Chart).

A sample of urine, taken at the end of the second day, possessed no antitoxic properties, although at that time the antitoxin was rapidly disappearing from the blood. This observation is in harmony with those of Bomstein and at variance with those of Dzerjgowsky ( 7 ). 
That the antitoxin mainly entered the blood, and was not uniformly distributed throughout the parenchyma of the organs and muscles, is shown by calculating the amount of antitoxin per gramme weight of animal. The ass weighed 160 kilos., and if the antitoxin units had been uniformly distributed, the amount per gramme should have been 15 , i.e., roughly speaking, 10 c.c. of blood should have contained 1.5 units, whereas at the end of twenty-four hours, experiment showed that the number of units per 10 c.c. was 16 .

Chart.

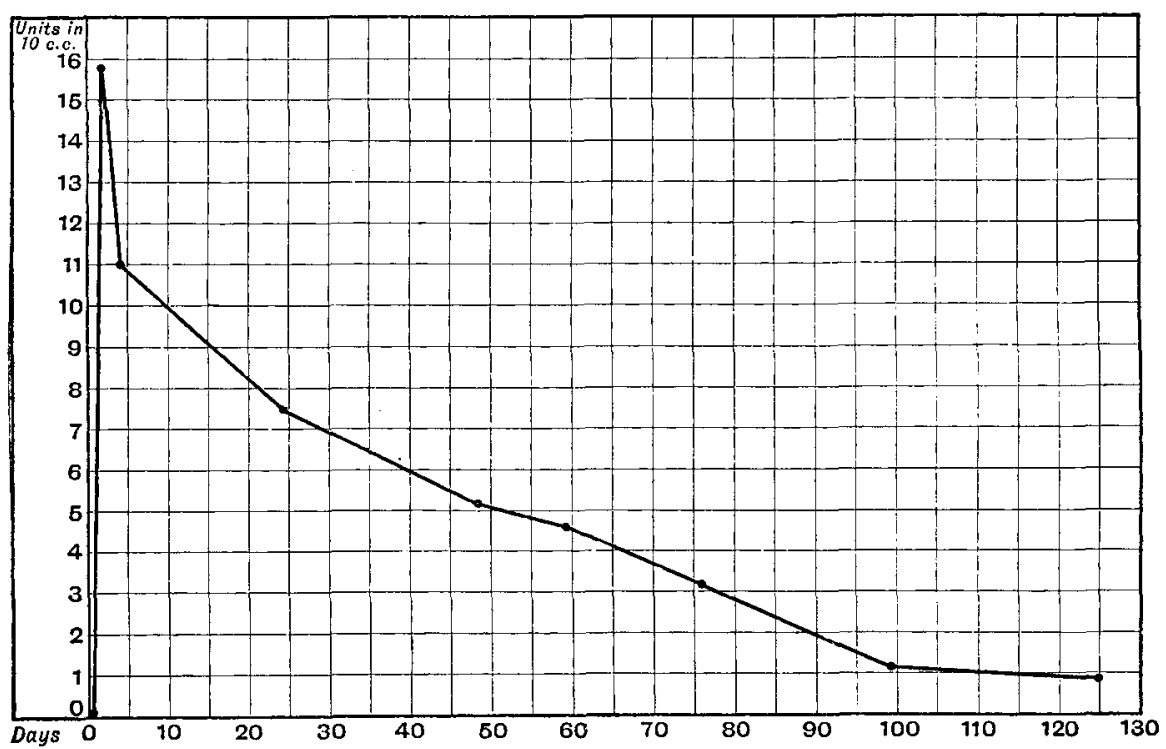

Reckoning the blood at one-thirteenth of the entire weight of the body, we may estimate that the animal had about 13 litres. Had all the antitoxin gone to the blood by its serotropic tendency there should have been theoretically 2 units of antitoxin per c.c. (20 units in 10 c.c.), which, allowing for experimental error, and the approximate estimate of the quantity of blood, comes near what was experimentally determined, namely, 16 units in 10 c.c.

From these facts we seem justified in concluding-(1) that almost the whole of the diphtheria antitoxin introduced subcutaneously rapidly enters the blood serum (serotropism); (2) that after a day or two it rapidly disappears; (3) that the disappearance is not due to excretion by the kidneys; (4) that the remainder persists, in gradually diminishing quantities, for a period varying probably with the amount of antitoxin introduced.

The experiments were performed in the laboratories of the British Institute of Preventive Medicine, to the council and director of which I tender my sincere thanks for the facilities which at all times they afforded in the work. 
The details of the estimation of the antitoxin in the various venesections are appended. ${ }^{1}$

Determination of Antitoxic Value of Serum.

1. Before Injection.

0.3 c.c. $\mathrm{T}+3$ c.c. $\mathrm{S}$. . . . . + death.

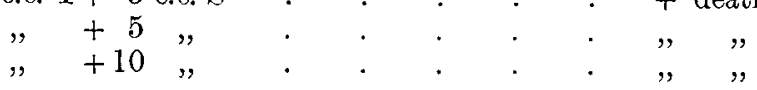

\section{First Venesection.}

$$
\begin{aligned}
& 0 \cdot 3 \text { c.c. } \mathrm{T}+1 \quad \text { c.c. } \mathrm{S} . \quad \text {. } \quad . \quad \text {. . . } \mathrm{O}
\end{aligned}
$$

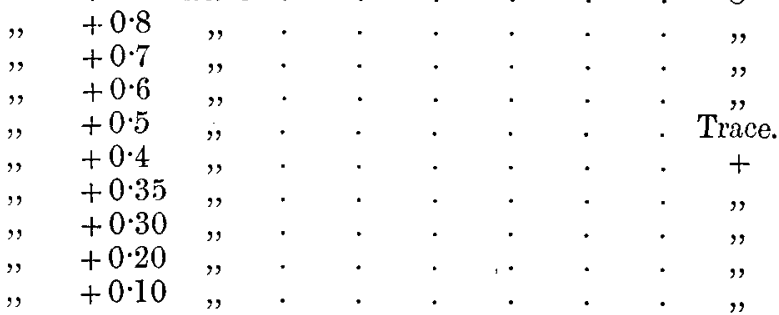

c.c. S. . . . . O O

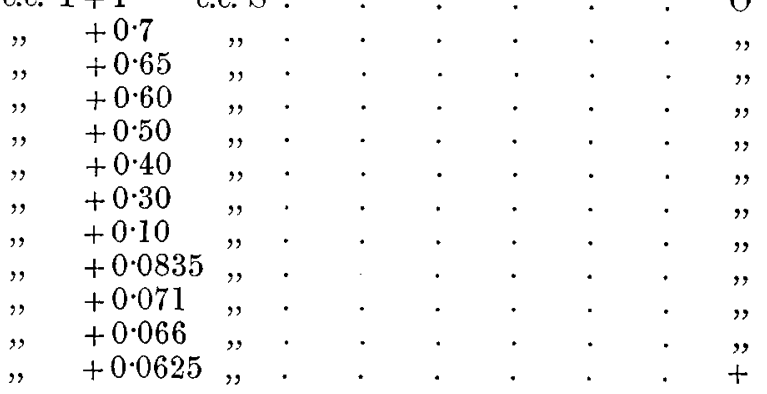

4. Third Venesection.

0.3 c.c. $\mathrm{T}+0.6$ c.c. $\mathrm{S}$

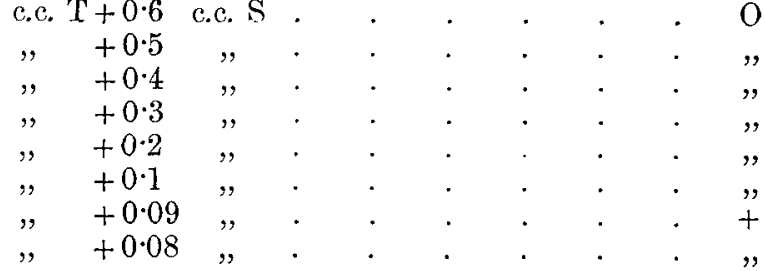

5. Fourth Venesection.

0.3 c.c. $\mathrm{T}+0.5$ c.c. $\mathrm{S}$

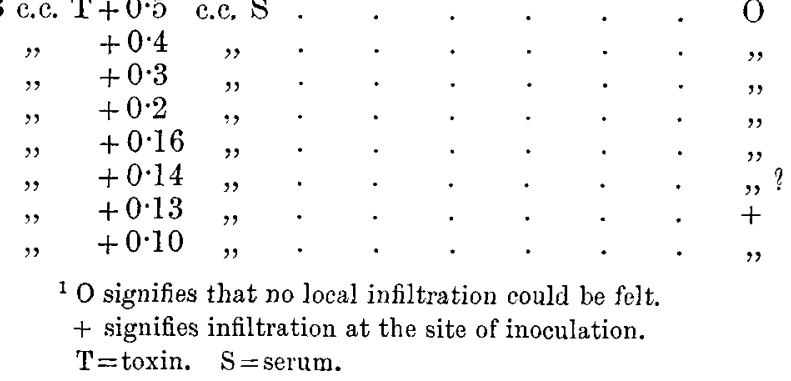


6. Fifth Venesection.

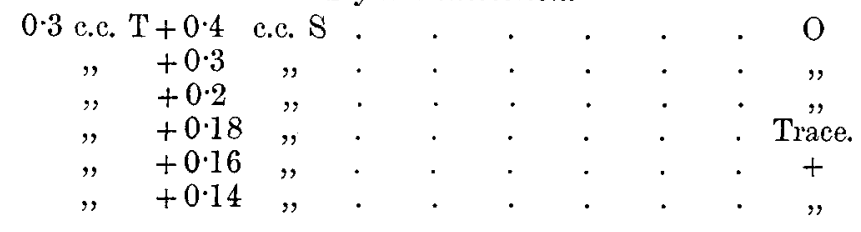

7. Sixth Venesection.

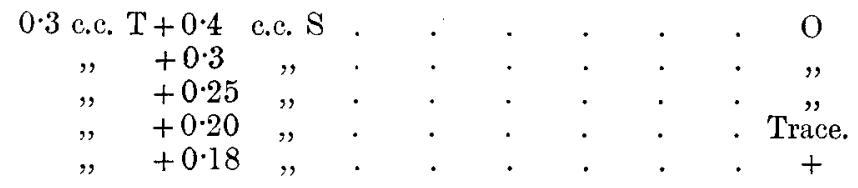

8. Seventh Venesection.

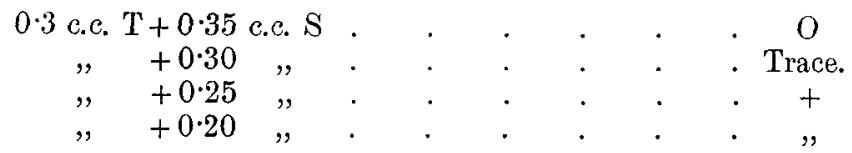

9. Eighth Venesection.

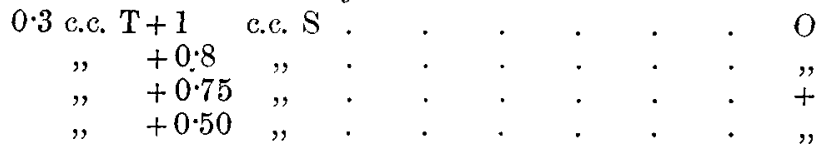

10. Ninth Venesection.

0.3 c.c. $\mathrm{T}+1.2$ c.c. $\mathrm{S}$.

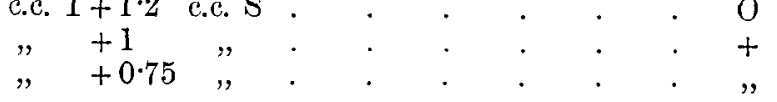

\section{BIBLIOGRAPHY.}

1. Ehrlich, . . . . . Deutsche med. Wehnschr., Leipzig, 1890, S. 977.

2. Behring, . . . . . Fortschr. d. Med., Berlin, 1897, Bd. xv. S. 1.

3. Passini, . . . . . Wien. klin. Wchnschr., 1896, No. 48.

4. Behring, . . . . . Loc. eit.

5. Rubers, . . . . . Deutsche med. Wehnschr., Leipzig, 1895, S. 758.

6. Bomstein, . . . . . Centralbl. f. Bakteriol. u. Parasitenk., Jena, 1897, Bd. xxii. S. 587.

7. Dzerjaowsky, . . . Arch. de sc. biol., St. Pétersbourg, 1897, tome v. Nos. 2 and 3. 